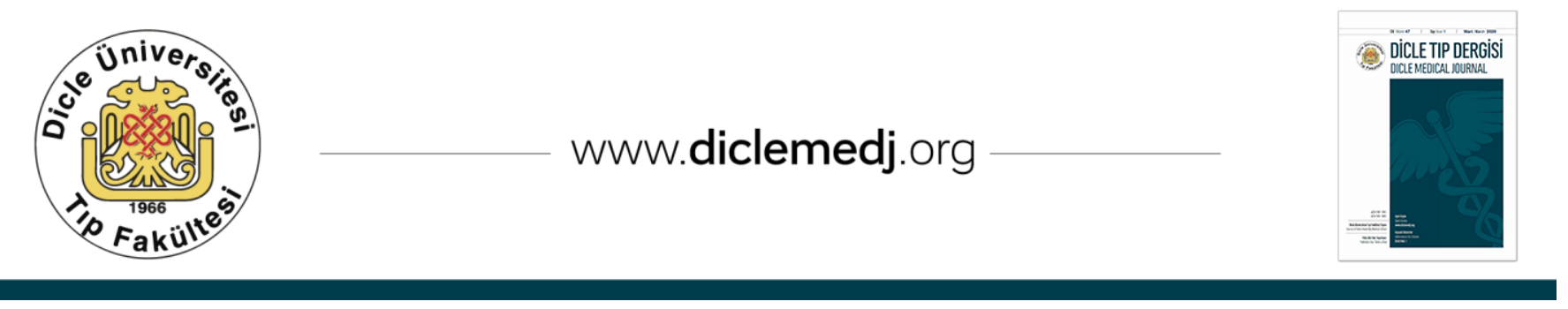

Özgün Araștırma / Original Article

\title{
Pulmoner Arteriyal Hipertansiyon Hastalarında Serum D vitamini Düzeyleri
}

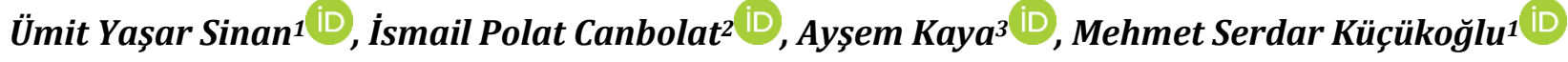 \\ 1 İstanbul Üniversitesi-Cerrahpaşa Kardiyoloji Enstitüsü, Kardiyoloji A.B.D., İstanbul, Türkiye \\ 2 İstanbul Bilim Üniversitesi Şişli Florans Nightingale Hastanesi, Kardiyoloji A.B.D., İstanbul, Türkiye \\ 3 İstanbul Üniversitesi-Cerrahpaşa Kardiyoloji Enstitüsü, Biyokimya A.B.D., İstanbul, Türkiye
}

Geliş: 07.02.2020; Revizyon: 11.02.2020; Kabul Tarihi: 17.02.2020

$\ddot{0} \mathbf{z}$

Amaç: Pulmoner arteriyal hipertansiyon (PAH) hastalarında D vitamini düzeylerinin sağlıklı gönüllülerden oluşan kontrol grubuyla kıyaslanması ve hastalık şiddetiyle D vitamini düzeyi arasındaki ilişkinin araștırılması.

Yöntemler: Çalışmamız tek merkezli, kesitsel bir çalışma olup, pulmoner hipertansiyon (PH) polikliniğimizde PAH tanısı ile takip edilen 36 hasta ve yaş-cinsiyet eşleştirilmiş 24 sağlıklı gönüllüden oluşmaktadır. PAH tanısı, güncel Avrupa Kardiyoloji Cemiyeti ve Avrupa Solunum Derneği 2015 PH kılavuzu tanı algoritması önerileri doğrultusunda konuldu. Kontrol grubu olarak, bilinen bir kardiyak veya sistemik-enflamatuvar hastalık öyküsü olmayan, herhangi bir ilaç kullanmayan, tüm sistem fizik muayenesi normal, elektrokardiyografik (EKG) ve ekokardiyografik (Eko) incelemede patoloji saptanmayan sağlıklı gönüllüler seçildi. Tüm hastalarda ve sağlıklı gönüllülerde sabah 8 saat açlık kan örnekleri alınarak, plazma 25-OH vitamin D düzeyleri ölçüldü (Elecsys® Vitamin D Testi).

Bulgular: Çalışma popülasyonumuz $36 \mathrm{PAH}$ hastası ve yaş-cinsiyet eşleştirilmiş 24 sağlıklı gönüllüden oluşmaktaydı. Hastaların 24 tanesinde (\%67) doğumsal kalp hastalığıla ilișkili PAH (PAH-DKH), 12 tanesinde (\%33) idiyopatik PAH (IPAH) mevcuttu. Tüm çalışma grubunun yaş ortalaması $41.4 \pm 14.0$ iken PAH hastaları ve kontrol grubunda yaş ortalaması benzerdi (median $42 \& 40$ yaş). Her iki grupta da kadın cinsiyet baskındı. Sağlıklı gönüllüler ve PAH hastaları arasında vücut kitle indeksi, kreatinin, ürik asit, hematokrit düzeyi açısından bir fark yoktu. Vitamin D düzeyleri ise PAH hastalarında ( $7.7 \pm 6.2 \mathrm{U} / \mathrm{L})$ sağlıklı gönüllülere göre $(21.9 \pm 14.1 \mathrm{U} / \mathrm{L})$ belirgin olarak düşük saptandı ( $<<0.001)$. Vitamin D düzeyi PAH hastalarında kontrol grubuna göre düşük saptanmakla birlikte, D vitamini düzeyi ile ne fonksiyonel kapasite (DSÖ FK III \& FK II), ne de altta yatan etiyolojik neden (PAH-DKH \& IPAH) arasında ilişki saptanamadı

Sonuçlar: Çalışmamızda serum D vitamini düzeyleri PAH hastalarında sağlıklı gönüllülere göre belirgin olarak daha düşüktü. Bununla birlikte PAH hastalarını altta yatan etiyolojik nedene göre incelediğimizde (IPAH \& PAH-DKH), D vitamini düzeyleri arasında farklılık yoktu.

DOI: $10.5798 /$ dicletip.706143

Yazışma Adresi / Correspondence: Ümit Yaşar Sinan, İstanbul Üniversitesi-Cerrahpaşa Kardiyoloji Enstitüsü, Kardiyoloji Ana Bilim Dalı, İstanbul, Türkiye e-mail: drumityasar@hotmail.com 
Anahtar kelimeler: D vitamini, pulmoner arteriyal hipertansiyon, fonksiyonel kapasite, kalsitriol.

\title{
Serum Vitamin D Levels in Patients with Pulmonary Arterial Hypertension
}

\begin{abstract}
Objective: To compare the vitamin D levels in patients with pulmonary arterial hypertension (PAH) with the control group of healthy volunteers and to investigate the relationship between disease severity and vitamin D level.

Methods: Our study is a single center, cross-sectional study consisting of 36 patients with pulmonary artery hypertension (PAH) followed-up by pulmonary hypertension (PH) outpatient clinic and 24 age-sex matched healthy volunteers. The diagnosis of PAH was confirmed according to the diagnostic algorithm of 2015 European Society of Cardiology and European Respiratory Society PH Guidelines. As the control group, healthy volunteers who do not have a known history of cardiac or systemic-inflammatory disease, do not use any medication, has normal physical, electrocardiographic (ECG) and echocardiographic examination were selected. In all groups, 8-h fasting blood samples were obtained in the morning and plasma $25-\mathrm{OH}$ vitamin D levels were measured by Elecsys ${ }^{\circledR}$ Vitamin D Test.

Results: Our study population consisted of $36 \mathrm{PAH}$ patients and 24 age-sex matched healthy volunteers. Twenty-four patients (67\%) had PAH associated with congenital heart disease related (PAH-CHD) and other 12 patients (33\%) had idiopathic PAH (IPAH). While the average age of the whole study group was $41.4 \pm 14.0$ years, the mean age was similar in the PAH patients and control group (median $42 \& 40$ years). Female sex was dominant in both groups. There was no difference between healthy volunteers and PAH patients in terms of body mass index, creatinine, uric acid and hematocrit levels. Vitamin D levels were significantly lower in PAH patients $(7.7 \pm 6.2 \mathrm{U} / \mathrm{L})$ than in healthy volunteers $(21.9 \pm 14.1$ $\mathrm{U} / \mathrm{L})(\mathrm{p}<0.001)$. Although vitamin D level was found to be lower in PAH patients compared to the control group, no relation was found between vitamin D level and neither functional capacity (WHO FC III \& FC II) nor the underlying etiological cause (PAH-CHD \& IPAH).
\end{abstract}

Conclusions: In our study, serum vitamin D levels were significantly lower in PAH patients than in healthy volunteers. However, when we examined PAH patients according to the underlying etiological cause (IPAH \& PAH-CHD), there was no difference between vitamin D levels.

Keywords: Vitamin D, pulmonary arterial hypertension, functional capacity, calcitriol.

\section{GİRiş}

Pulmoner hipertansiyon (PH), sağ kalp kateterizasyonu (SKK) yöntemiyle, istirahatte, sırt üstü yatar pozisyonda ölçülen ortalama pulmoner arter basıncının (oPAB) $\geq 25 \mathrm{mmHg}$ olması olarak tanımlanmaktadır ${ }^{1}$. Pulmoner arteriyal hipertansiyon (PAH) terimi ise hemodinamik olarak prekapiller $\mathrm{PH}$ (oPAB $\geq 25$ mmHg, pulmoner kapiller uç basıncı-PKUB $\leq 15$ mmHg ve pulmoner vasküler direnç-PVD $>3$ Wood ünitesi-WU) ile karakterize bir grup hastalığı ifade etmektedir ${ }^{1}$. Bir hasta PAH (grup $1 \mathrm{PH}$ ) olarak siniflandırılmadan önce, prekapiller $\mathrm{PH}$ 'e neden olabilecek diğer hastalıklar (akciğer hastalığına bağlı PH, kronik tromboembolik PH-KTEPH, ve diğer nadir hastalıklar) dışlanmalıdır ${ }^{1}$ Patofizyolojik olarak ise PAH, PVD artışına ikincil sağ kalp yetersizliğine yol açan, küçük pulmoner arterlerde yeniden şekillenme (pleksiform lezyonlar) ile karakterizedir².

Tipik olarak fosfor, kalsiyum metabolizmasını düzenleyen ve eksikliği kemik hastalıkları ile ilişkili (raşitizm ve osteomalazi) olan D vitaminin, çeşitli yolaklar üzerinden miyokart yapı ve/veya fonksiyonunu etkilediği gösterilmiştir. Kardiyomiyosit, damar düz kas hücresi ve endotel hücresi gibi kardiyovasküler sistemle ilişkili çeşitli dokularda D vitamini reseptörlerinin yer aldığı bilinmektedir ${ }^{3,4}$.

İlginç olarak D vitaminin aktif şekli olan kalsitriolün, PAH ile ilişkili çeşitli sinyal 
yolaklarını düzenlediği bilinmektedir. Vitamin D reseptörü, PAH patofizyolojisinde yer alan ve hastalığa neden olan aşırı veya az aktif bazı genleri baskılamaktadır. Çalışmamızda bu ilişkiden yola çıkarak, PAH hastalarında D vitamini düzeylerini sağlıklı gönüllülerden oluşan kontrol grubuyla kıyaslamayı ve hastalık şiddetiyle D vitamini düzeyi arasındaki ilişkiyi araştırmayı amaçladık.

\section{YÖNTEMLER}

Çalışmamız tek merkezli, kesitsel bir çalışma olup, $\mathrm{PH}$ polikliniğimizde $\mathrm{PAH}$ tanısı ile takip edilen 36 hasta ve yaş-cinsiyet eşleştirilmiş 24 sağlıklı gönüllüden oluşmaktadır. Hastalarımızda $\mathrm{PAH}$ tanısı, güncel Avrupa Kardiyoloji Cemiyeti ve Avrupa Solunum Derneği 2015 PH kılavuzu tanı algoritması önerileri doğrultusunda konuldu. Buna göre semptom, hikaye ve fizik muayene bulguları PH düşündüren hastalarda, ayırıcı tanı yöntemleri (elektrokardiyografi, akciğer grafisi, solunum fonksiyon testi, arter kan gazı incelemesi, laboratuvar tetkikleri ve ekokardiyografi) kullanılarak PH açısından orta-yüksek risk taşıyan hastalarda, sol kalp hastalığına bağlı PH (grup $2 \mathrm{PH}$ ), akciğer hastalığına bağlı PH (grup $3 \mathrm{PH}$ ) ve KTEPH (grup $4 \mathrm{PH}$ ) gibi PH'na yol açan sık hastalıklar (yaklaşık hastaların \%90-95'i) ileri tetkikler uygulanarak (ekokardiyografi, ventilasyon/perfüzyon sintigrafisi ve bilgisayarlı tomografi) dışlandıktan sonra, tüm hastalarda PAH (grup $1 \mathrm{PH}$ ) tanısı SKK ile doğrulandı. Femoral ven yoluyla istirahatte ve sırt üstü yatar pozisyonda yapılan SKK sırasında oPAB $\geq 25 \mathrm{mmHg}$, PKUB $\leq 15 \mathrm{mmHg}$ ve PVD $>3$ WU olan hastalar PAH (grup $1 \mathrm{PH}$ ) olarak kabul edildi.

Kontrol grubu olarak, bilinen bir kardiyak veya sistemik-enflamatuvar hastalı öyküsü olmayan, herhangi bir ilaç kullanmayan, tüm sistem fizik muayenesi normal, elektrokardiyografik (EKG) ve ekokardiyografik (Eko) incelemede patoloji saptanmayan sağlıklı gönüllüler seçildi.
Tüm PAH hastalarında fonksiyonel sınıf (FK; DSÖ kriterlerine göre), 6 dakika yürüme testi (6-DYT, metre), eko parametreleri (zirve triküspit yetersizliğinden hesaplanan sistolik $\mathrm{PAB}$, triküspit anulusunun sistolik yer değiştirmesi-TAPSE, să atriyum alanı, perikardiyal efüzyon varlığı), risk biyobelirteçleri (natriüretik peptidler) ve SKK ile detaylı hemodinamik değerlendirme yapıldı. Tüm hastalarda ve sağlıklı gönüllülerde sabah 8 saat açlık kan örnekleri alınarak, plazma $25-\mathrm{OH}$ vitamin D düzeyleri ölçüldü (Elecsys® Vitamin D Testi). Daha önceden ostoeporoz nedeniyle vitamin D veya kalsiyum takviyesi alan, hiperparatoroidizm tanılı ve kronik diyaliz tedavisi alan hastalar çalışmadan dışlandı.

Çalışma için etik kurul onayı alınmış, tüm hastalar çalışma hakkında bilgilendirilmiş ve çalışmaya katılmak için gönüllü oldukları takdirde bilgilendirmiş olur formu imzalatılmıştır.

\section{İstatiksel Analiz}

Analiz için SPSS Statistics for Windows, Version 21.0 (IBM Corp., Armonk, NY, USA) kullanıldı. Sürekli değişkenler mean \pm SD veya median (minimum-maksimum) olarak, kategorik değişkenler yüzde olarak ifade edildi. Hasta ve sağlıklı gönüllülerin kategorik değişkenleri kikare (x2) testiyle karşılaştırılırken, D vitamini düzeyleri Student's t testiyle karşılaştırıldı. $\mathrm{P}$ değeri $<0.05$ anlamlı olarak kabul edildi.

\section{BULGULAR}

Çalışma popülasyonumuz 36 PAH hastası ve yaş-cinsiyet eşleştirilmiş 24 sağlıklı gönüllüden oluşmaktaydı. Hastaların 24 tanesinde (\%67) doğumsal kalp hastalığıyla ilişkili PAH (PAHDKH), 12 tanesinde (\%33) idiyopatik PAH (IPAH) mevcuttu. Tüm çalışma grubunun yaş ortalaması $41.4 \pm 14.0$ iken PAH hastaları ve kontrol grubunda yaş ortalaması benzerdi (median $42 \& 40$ yaş). Her iki grupta da kadın cinsiyet baskındı. PAH grubunda hastaların 
\%75’i (27/36) kadın iken, bu oran kontrol grubunda \%71'di $(17 / 24)$. PAH hastalarının büyük çoğunluğu DSÖ-FK II hastalardan oluşmaktaydı (N:26, \%72). Geri kalan 10 hastada ise fonksiyonel kapasite DSÖ-FK III (N:10, \%28) olarak saptandı (Tablo 1).

Tablo I. PAH hastalarının ve kontrol grubunun klinik karakteristik özellikleri.

\begin{tabular}{|l|l|l|l|}
\hline Parametre & PAH (N:36) & $\begin{array}{l}\text { Kontrol grubu } \\
\text { (N:24) }\end{array}$ & P değeri \\
\hline Yaş (yıl, median) & 42 & 40 & 0,564 \\
\hline $\begin{array}{l}\text { Kadın cinsiyet N } \\
(\%)\end{array}$ & $27(\% 75)$ & $17(\% 72)$ & 0,784 \\
\hline VKI (kg/m²) & $25.4 \pm 4$ & $25.2 \pm 5$ & 0.625 \\
\hline $\begin{array}{l}\text { DSÖ FK II N (\%) } \\
\text { DSÖ FK III (N, \%) }\end{array}$ & $\begin{array}{l}26(\% 72) \\
\text { Vit D (U/L) }\end{array}$ & - & \\
\hline Htc (\%) & $7.7 \pm 6.2$ & $21.9 \pm 14.1$ & $<\mathbf{0 . 0 0 1}$ \\
\hline Kreatinin (mg/dl) & $0.84 \pm 0.8$ & $0.78 \pm 0.4$ & 0.456 \\
\hline Ürik asit (mg/dl) & $6.7 \pm 2.1$ & $5.4 \pm 2.4$ & 0.657 \\
\hline LVEF (\%, median) & 60 & 60 & 0.554 \\
\hline LVDD (mm) & $42.4 \pm 5.0$ & $48.0 \pm 4.0$ & 0.723 \\
\hline LA (mm) & $37.6 \pm 1.2$ & $35.8 \pm 1.7$ & 0.624 \\
\hline RVDD (mm) & $42.4 \pm 2.1$ & $24.5 \pm 1.2$ & $<\mathbf{0 . 0 0 1}$ \\
\hline $\begin{array}{l}\text { TAPSE (< 16mm, } \\
\%)\end{array}$ & 80 & - & $<\mathbf{0 . 0 0 1}$ \\
\hline sPAB (mmHg) & $75.5 \pm 11.6$ & $14.3 \pm 2.7$ & \\
\hline NT-proBNP & $703,7 \pm 861,3$ & $40,4 \pm 45,6$ & \\
\hline
\end{tabular}

Kısaltmalar: DSÖ FK; Dünya Sağlık Örgütü fonksiyonel kapasite, Htc; hematokrit, LA; sol atriyum çapl, LVDD; sol ventrikül diyastolik çap, LVEF; sol ventrikül ejeksiyon fraksiyonu, NTproBNP; N terminal pro B tipi natriüretik peptid, PAH; pulmoner arteriyal hipertansiyon, RVDD; sağ ventrikül diyastolik çap, TAPSE; triküspit anulusunun sistolik yer değiştirmesi, VKI; vücut kitle indeksi.

Sağlıklı gönüllüler ve PAH hastaları arasında vücut kitle indeksi, kreatinin, ürik asit, hematokrit düzeyi açısından bir fark yoktu. Vitamin D düzeyleri ise PAH hastalarında $7.7 \pm$ $6.2 \mathrm{U} / \mathrm{L})$ sağlıklı gönüllülere göre $(21.9 \pm 14.1$ $\mathrm{U} / \mathrm{L})$ belirgin olarak düşük saptandı $(\mathrm{p}<0.001)$ (Tablo 1). Sağ ventrikül fonksiyon bozukluğunun dolaylı göstergesi olarak $\mathrm{N}$ terminal pro B tipi natriüretik peptid düzeyleri
(NT-proBNP) PAH hastalarında belirgin olarak daha yüksekti $(703,7 \pm 861,3 \mathrm{pg} / \mathrm{ml} \& 40,4 \pm$ $45,6 \quad \mathrm{pg} / \mathrm{ml}, \quad \mathrm{p}<0.001)$. Ekokardiyografik incelemede, her 2 grupta da sol ventrikül ve sol atriyum çapı, sol ventrikül ejeksiyon fraksiyonu (EF) benzer iken, PAH hastalarında sağ kalp boşlukları daha geniş, sPAB daha yüksek ve sağ ventrikül fonksiyon bozukluğuna (TAPSE $<16$ $\mathrm{mm}$ ) daha sık rastlanmaktaydı (Tablo 1).

Vitamin D düzeyi PAH hastalarında kontrol grubuna göre düşük saptanmakla birlikte, D vitamini düzeyi ile ne fonksiyonel kapasite (DSÖ FK III \& FK II), ne de altta yatan etiyolojik neden (PAH-DKH \& IPAH) arasında ilişki saptanamadı (Tablo 2).

Tablo II. PAH hastalarında ve kontrol grubunda etiyolojik nedene ve fonksiyonel kapasiteye göre $\mathrm{D}$ vitamini düzeyleri.

\begin{tabular}{|cc|l|l|}
\hline \multicolumn{1}{|l|}{ Değişken } & D vit. düzeyi (U/L) & P değeri \\
\hline Etiyolojik neden & & \\
- & IPAH & $6.4 \pm 5.3$ & 0.416 \\
- & PAH-DKH & $8.2 \pm 6.8$ & \\
\hline DSÖ FK & & & \\
- & FK II & $7.7 \pm 6.5$ & 0.990 \\
- & FK III & $7.5 \pm 5.9$ & \\
\hline
\end{tabular}

Kısaltmalar: DSÖ FK; Dünya Sağlık Örgütü fonksiyonel kapasite, IPAH; idiyopatik PAH, PAH; pulmoner arteriyal hipertansiyon, PAH-DKH; doğumsal kalp hastalı̆̆ıla ilişkili PAH.

\section{TARTIŞMA}

Pulmoner hipertansiyon, PVD'de ilerleyici artışa bağlı sağ ventrikül fonksiyon bozukluğu ve kalp yetersizliği ile karakterize, engelleyici ve potansiyel olarak ölümcül bir durumdur. Tedavide kullanılan ajanlar hastalık patofizyolojisiyle ilişkili olan 3 yolağ (endotelin, nitrik oksit ve prostasiklin yolağını) hedef almaktadır. Ayrıca altta yatan hastalığa neden olabilecek veya tetikleyebilecek nedenler (hipoksi, demir eksikliği, enfeksiyon, D vitamini eksikliği) düzeltilmelidir ${ }^{1}$.

Vitamin D eksikliği dünya çapında bir salgın olarak kabul edilmektedir. Eksikliği başlıca iskelet sistemi olmak üzere (raşitizm ve osteomalazi), pek çok sistemi olumsuz 
etkilemektedir. D vitamini çeșitli yolaklar üzerinden kan basıncını düzenlemektedir ve düzeyi serum renin aktivitesiyle ters ilişkilidir. Vitamin D eksikliği renin anjiyotensin aldosteron sistemini (RAAS) aktive eder ve RAAS aktivasyonu PH ile ilişkilidir ${ }^{5}$. Aradaki sebep-sonuç ilişkisi tam olarak kanıtlanmamış olsa da, bazı eski çalışmalar PH hastalarında D vitamini eksikliği sıklı̆̆ının yüksek olduğunu göstermişlerdir ${ }^{6-9}$. Vitamin D reseptörü, $\mathrm{PAH}$ patofizyolojisinde yer alan ve hastalığa neden olan aşırı veya az aktif bazı genleri baskılamaktadır.

Çalışmamızda serum D vitamini düzeyleri PAH hastalarında sağlıklı gönüllülere göre belirgin olarak daha düşüktü. Bununla birlikte $\mathrm{PAH}$ hastalarını altta yatan etiyolojik nedene göre incelediğimizde (IPAH \& PAH-DKH), D vitamini düzeyleri arasında farklılık yoktu (her iki grupta da kontrol grubuna göre düşük). Hastalık ciddiyetine göre D vitamini düzeyini karşılaştırdığımızda (DSÖ FK III \& II) yine gruplar arasinda fark saptayamadık. Ancak çalışmamızda sadece DSÖ FK II ve III hastalar bulunmaktaydı. Fonksiyonel kapasitesi daha kötü (DSÖ FK IV) ve tamamen normal (DSÖ FK I) hastaların olmaması hastalık ciddiyeti ile D vitamini düşüklügü arasında bir korelasyon saptamamızın nedeni olabilir.

Vitamin D'nin aktif formu olan kalsitriol, PAH patofizyolojisinde rolü olan bazı yolakları düzenlemektedir. D vitamin düzeyleri düşük olan PAH-hayvan modellerinde, PAB artışı ve PA arterlerde artmış düz kas hücre miktarı (muskülarinizasyon) gösterildi. Beş hafta boyunca normal diyetle veya $\mathrm{D}$ vitamininden fakir diyetle beslenen sıçanlar ardından SU5416 $(20 \mathrm{mg} / \mathrm{kg})+2$ hafta hipoksi (\%10 oksijen) veya normoksi + plasebo koluna randomize edildiğinde, vitamin $\mathrm{D}$ düzeyi düşük olan sıçanlarda endotel disfonksiyonu (azalmış asetilkolin aracılı gevşeme ve azalmış TASK1 potasyum yoğunluğu) meydana gelmiş ve bu sıçanlarda PAB ve PVD yüksek bulunmuștur ${ }^{10,11}$. Plazma örnekleri CIBERES Biyobankasından ve klinik parametreleri Spanish Pulmonary Arterial Hypertension Registry (REHAP) kayıt çalışmasından elde edilen 67 İspanyol PAH hastasının retrospektif analizinde, PAH hastalarının \%95'nde D vitamini eksikliği $(<20 \mathrm{ng} / \mathrm{ml})$ olduğu ve bu hastaların \%70'nde de D vitamini düzeylerinin ciddi düzeyde $(<10 \mathrm{ng} / \mathrm{ml})$ düşük olduğu saptand $1^{12}$. Yine bu hasta grubu detaylı olarak incelendiğinde $\mathrm{D}$ vitamini düzeyi $<7.17 \mathrm{ng} / \mathrm{ml}$ olanlarda fonksiyonel kapasitenin daha kötü, 6DYT mesafelerinin daha az, BNP düzeylerinin daha yüksek, TAPSE'nin daha düşük ve sağkalımlarının daha kötü olduğu tespit edildi ${ }^{12}$. Diğer bir çalışmada Atamanuk ve ark. D vitamini düzeyinin $\mathrm{PH}$ hastalarında sağlıklı gönüllülere ve düşük EF'li hastalara göre daha düşük olduğunu ve 6-DY mesafesiyle D vitamini arasında korelasyon olduğunu gösterdiler ${ }^{13}$.

Sonuç olarak çalışmamızda PAH hastalarında D vitamini düzeyinin sağlıklı gönüllülere göre düşük olduğunu saptadık. Ancak bu düşüklük hastalık ciddiyeti (fonksiyonel kapasiteye göre) ve etiyolojik nedenden bağımsızdı. Vitamin D eksikliğinin PAH'ın nedeni mi, tetikleyicisi mi yoksa hastalığı hızlandırıcı bir durum mu olduğu açık değildir. Yine PAH başlı başına doğrudan $\mathrm{D}$ vitamini düşüklüğüne neden olabilir. Bir diğer teoride $\mathrm{PAH}$ ve $\mathrm{D}$ vitamini arasında ilişki olmadığı ve bu 2 durumun tesadüfen birlikte varlığının kafa karıştıııcı olabileceğidir. Bugün elimizde var olan kanitlar ışığında PAH hastalarının çoğunluğunda D vitamini düzeylerinin düşük olduğunu ve bu hastalarda Vitamin D reseptör sayısının sağlıklı bireylere göre düşük olduğunu söyleyebiliriz. Yine D vitamini eksikliğinin $\mathrm{PH}$ 'nu ağırlaştırdığını hayvan modellerinden elde edilen sonuçlara göre biliyoruz. Bütün bu bulgular D vitamini eksikliğinin $\mathrm{PAH}$ patofizyolojisinde etkili olduğunu düşündürmekle birlikte, vitamin $\mathrm{D}$ takviyelerinin düşük $\mathrm{D}$ vitamini olan $\mathrm{PAH}$ 
hastalarında ișe yarayıp yaramadığını gösterecek randomize kontrollü çalışmalara ihtiyacımız var. Çalışmamızın kısıtlılıkları; 1. Tüm grup 1 PAH hastalarını (ilaçla ilişkili, kalıtımsal, bağ dokusu hastalığı, ilaç-toksin, HIV ile ilişkili ve porto-pulmoner PAH) içermemesi, 2. Hastaların D vitamini düzeyine göre düşük (<20 ng/ml) veya ciddi düşük $(<10 \mathrm{ng} / \mathrm{ml})$ olarak sınıflandırılmaması olarak sayılabilir. Ancak hasta grubumuzda ortalama D vitamin düzeyi $7.7 \pm 6.2 \mathrm{U} / \mathrm{L}$ olup, bu değerler ciddi $\mathrm{D}$ vitamini düzey düşüklügünü göstermektedir.

Etik Kurul Kararı: Çalışma için etik kurul onayı alınmış, tüm hastalar çalışma hakkında bilgilendirilmiş ve çalışmaya katılmak için gönüllü oldukları takdirde bilgilendirmiş olur formu imzalatılmıştır.

Çıkar Çatışması Beyanı: Yazarlar çıkar çatışması olmadığını bildirmişlerdir.

Finansal Destek: Bu çalışma her hangi bir fon tarafından desteklenmemiştir.

Declaration of Conflicting Interests: The authors declare that they have no conflict of interest.

Financial Disclosure: No financial support was received.

\section{KAYNAKLAR}

1. Galiè N, Humbert M, Vachiery JL, et al. ESC Scientific Document Group. 2015 ESC/ERS Guidelines for the diagnosis and treatment of pulmonary hypertension: The Joint Task Force for the Diagnosis and Treatment of Pulmonary Hypertension of the European Society of Cardiology (ESC) and the European Respiratory Society (ERS): Endorsed by: Association for European Paediatric and Congenital Cardiology (AEPC), International Society for Heart and Lung Transplantation (ISHLT). Eur Heart J 2016; 37: 67-119.

2. Farber HW, Loscalzo J. Pulmonary arterial hypertension. N Engl J Med 2004; 351: 1655-65.
3. Walters MR, Wicker DC, Riggle PC. 1,25dihydroxyvitamin $\mathrm{D} 3$ receptors identified in the rat heart. J Mol Cell Cardiol 1986; 18: 67-72.

4. Somjen D, Weisman Y, Kohen F, et al. 25hydroxyvitamin D3-1alpha-hydroxylase is expressed in human vascular smooth muscle cells and is upregulated by parathyroid hormone and estrogenic compounds. Circulation 2005; 111: 1666-7.

5. Bogaard HJ, Al Husseini A, Farkas L. Severe pulmonary hypertension: the role of metabolic and endocrine disorders. Pulm Circ 2012; 2: 148-54.

6. Demir M, Uyan U, Keceoclu S, et al. The relationship between vitamin $\mathrm{D}$ deficiency and pulmonary hypertension. Prague Med Rep 2013; 114: 154-61.

7. Thadhani R, Appelbaum E, Pritchett Y. Vitamin D therapy and cardiac structure and function in patients with chronic kidney disease: the PRIMO randomized controlled trial. JAMA 2012; 307: 674-84.

8. Mirdamadi A, Moshkdar P. Benefits from the correction of vitamin D deficiency in patients with pulmonary hypertension. Caspian J Intern Med 2016; 7: 253-9.

9. Rios Fernández R, Fernández Roldán $\mathrm{C}$, Callejas R, et al. Vitamin D deficiency in a cohort of patients with systemic scleroderma from the south of Spain. J Rheumatol 2010; 37: 1355.

10. Abe K, Toba M, Alzoubi A, et al. Formation of plexiform lesions in experimental severe pulmonary arterial hypertension. Circulation 2010; 121: 2747-54.

11. Jiang B, Deng Y, Suen C, et al. Marked strainspecific differences in the SU5416 rat model of severe pulmonary arterial hypertension. Am J Respir Cell Mol Biol 2016; 54: 461-8.

12. Callejo M, Morales-Cano D, MondejarParreno G, et al. Possible pathophysiological 
role of vitamin D deficit in pulmonary arterial hypertension. Eur Respir J 2018; 52: 3083

13. Atamanuk AN, Litewka DF, Baratta SJ, et al. Vitamin D deficiency among patients with pulmonary hypertension. BMC Pulmonary Medicine 2019; 19: 258. 